\title{
Relationship between Sap prevalence and biofilm formation among resistant clinical isolates of Candida albicans
}

\author{
Ashraf A Kadry ${ }^{1}$, Amira M El-Ganiny ${ }^{1}$, Ahmed M El-Baz ${ }^{2}$
}

1. Department of Microbiology and Immunology- Faculty of Pharmacy- Zagazig University-Zagazig-Egypt.

2. Department of Microbiology and Biotechnology-Faculty of Pharmacy- Delta University for Science and Technology- International coastal road, Gamasa city, Mansoura, Dakhaliya Egypt.

\begin{abstract}
Background: Fungal infections represent a serious health problem especially in immunocompromised individuals. Candida albicans is the most common fungi that cause superficial and systemic infections with high mortality rates. Anti-fungal resistance of C. albicans may be attributed to its virulence. Biofilm formation and proteolytic activity are major virulence determents that may influence both pathogenicity and anti-fungal resistance of Candida albicans.

Objective: This work studied the relation between biofilm formation, proteolytic activity and prevalence of some Sap genes with reduced susceptibility of C. albicans to different anti-fungal agents.

Methods: Fifty three C. albicans strains isolated from patients with systemic infections, identified by germ tube, chromogenic agar and confirmed by PCR, were subjected to evaluate their proteolytic activity, the degree of biofilm production and the prevalence of Sap9 and Sap10 genes. The susceptibility of the isolates was determined by disk diffusion method against five antifungal drugs.

Results and conclusion: Four of the $C$. albicans isolates were resistant to 3 anti-fungal drugs, strong biofilm producer, have proteolytic activity and contain either Sap9 or Sap10 or both. Conclusively, although anti-fungal resistance among the isolates was rare, a relation between the anti-fungal resistance and some major virulence factors was evidently proved in this study.
\end{abstract}

Keywords: Candida albicans, resistance, biofilm, proteolytic, Sap.

DOI: https://dx.doi.org/10.4314/ahs.v18i4.37

Cite as: Kadry AA, El-Ganiny AM, El-Baz. AM. Relationship between Sap prevalence and biofilm formation among resistant clinical isolates of Candida albicans. Afri Health Sci. 2018;18(4): 1166-1174. https://dx.doi.org/10.4314/abs.v18i4.37

\section{Introduction}

Candida infections have a significant rise in morbidity and mortality, especially in recent years due to the continuous increase in the number of immunosuppressive pa-

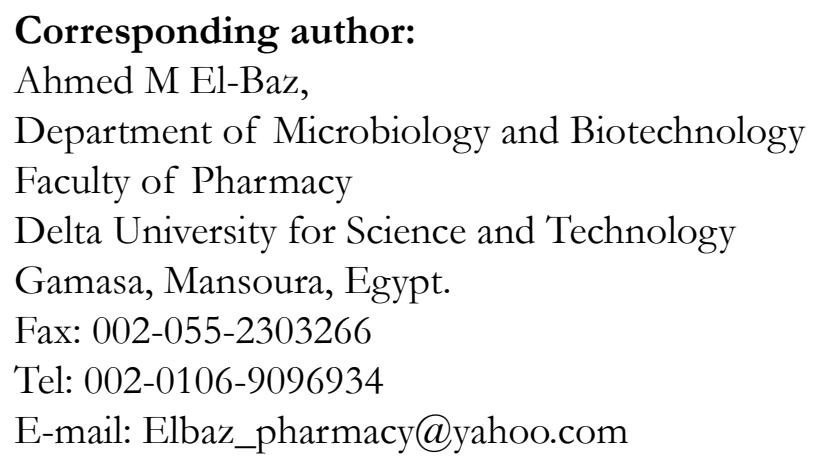

tients $^{1}$. Candida albicans is determined as the major human pathogen in the genus Candida ${ }^{2}$. C. albicans is classified as commensal fungi that present in ' many anatomical sites of the human body ${ }^{3}$. C. albicans can cause oral and vaginal infections as well as systemic diseases ${ }^{4}$. The rise in the incidence of Candida infections is complicated by the antimicrobial resistance and the limited number of available anti-fungal drugs ${ }^{5}$.

The ability of Candida to cause infection depends mainly on its intrinsic virulence attributes ${ }^{6}$. C. albicans cause critical problems because it has more virulence factors than non-Candida albicans isolates ${ }^{7}$. C. albicans has several virulence factors including phenotyping changes, biofilm formation, and production of harmful substances to cells, such as haemolysins, phospholipases and proteases as well as the ability to resist hydrogen peroxide ${ }^{8}$.

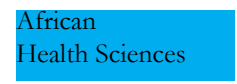

(C) 2018 Kadry et al. Licensee African Health Sciences. This is an Open Access article distributed under the terms of the Creative commons Attribution License (https://creativecommons.org/licenses/BY/4.0), which permits unrestricted use, distribution, and reproduction in any medium, provided the original work is properly cited. 
Among the hydrolytic enzymes that secreted by Candida spp. are the aspartic proteases which represent one of the major virulence determinants as they have a potential role in pathogenicity through facilitating the invasion and counteracting the host defense system? .

Secreted aspartic proteases (Saps), encoded by a family of 10 sap genes (sap1-sap10) which have a vital role in virulence of $C$. albicans by degrading host tissue proteins as well as adhere to epithelial host tissue ${ }^{10}$. Saps have a broad substrate specificity of human proteins such as albumin, haemoglobin, keratin, collagen, laminin, fibronectin, mucin and almost all immunoglobulins, including immunoglobulin $A$, which is resistant to the majority of bacterial proteases $^{11}$. A correlation between the expansion of sap genes and the transition from commensal to pathogenic microorganisms has been reported ${ }^{12}$. Non-pathogenic Candida spp. usually has fewer genes encoding Sap than pathogenic species and this fact was confirmed by gene sequencing. However, this rule cannot be applied to species such as C. glabrata or C. krusei, which do not possess any sap genes ${ }^{12}$. On the other hand, there is a correlation reported between Sap proteinase production and biofilm formation $^{13}$.

Biofilms are defined as self-derived extracellular matrix that produced by the microbial population attached to abiotic surface including biomedical devices or biotic surfaces including oral and vaginal mucosa ${ }^{14,15}$. C. albicans present in biofilm structure show a decrease in susceptibility to some anti-fungals as well as a reduction in killing by the host immune system ${ }^{16}$. Sap 9 and Sap10 enzymes maintain cell surface integrity of the Candida cell wall, and promote biofilm formation ${ }^{17}$.

This study aims to correlate between sap9 and sap10 prevalence and its role in biofilm formation and drug resistance among clinical isolates of C. albicans.

\section{Materials and methods Candida albicans isolates}

All the clinical specimens were collected under ethical standards from different Departments at Mansoura University Hospitals, and identified according to Cheesbrough $^{18}$. Briefly, the specimens were inoculated on Sabouraud dextrose agar (SDA) plates and incubated at $37^{\circ} \mathrm{C}$ for 24-48 hr. The suspected colonies of C. albicans were examined for their colonial morphology, Gram staining, germ tube formation, culture characteristics on Candida chromogenic agar (Pronadisa Co., Madrid, Spain) and the identification was confirmed by $\mathrm{PCR}^{19}$, The standard strain of Candida albicans (ATCC 10231) was included in this study.

\section{Determination of anti-fungal susceptibility by disk diffusion method}

Candida albicans isolates were tested for their susceptibility to different anti-fungal agents by disk diffusion method according to CLSI guideline ${ }^{20}$. The tested disks that in-

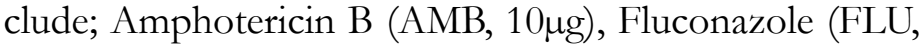
$25 \mu \mathrm{g})$, Voriconazole (VOR, $1 \mu \mathrm{g})$, Fluorocytosine (5FC, $1 \mu \mathrm{g})$, Caspofungin (CASP, $5 \mu \mathrm{g})$; were obtained from Bioanalyse, Turkey.

\section{Phenotypic detection of aspartyl proteinase activity in C. albicans isolates}

Briefly, Candida isolates were cultured in YEPD medium ( $2 \%$ glucose, $1 \%$ yeast extract, and $2 \%$ Bactopeptone) and then they induced to secrete proteinases onto the bovine serum albumin (BSA) agar. Filter paper disks, 6 $\mathrm{mm}$ diameter, were dipped into a suspension of Candida culture at a density of $10^{7}$ cell $\mathrm{mL}^{-1}$ ( $\left.0.5 \mathrm{McFarland}\right)$ in YEPD medium and applied to BSA agar plate. A maximum of 4 disks was used for each $9 \mathrm{~cm}$ diameter plate. The plates were incubated at $28^{\circ} \mathrm{C}$ for 7 days. The plates were observed daily for opacity around the disks, the opacity caused by albumin precipitation was observed for subsequent clearing due to hydrolysis by the acid proteinases of the fungi. The millimetric zones were evaluated as negative $(-)$ for no clearance, positive $(+)$ for mild activity (lysis zone of 1-2 $\mathrm{mm}$ around the disk), and double-positive $(++)$ for strong activity (lysis zone of 3-5 mm). The standard strain was used as positive controls, and the experiment was performed in triplicate ${ }^{21}$.

\section{Genotypic detection of Sap9 and Sap10 in Candida albicans isolates using PCR}

DNA of Candida albicans was extracted by colony PCR method ${ }^{22}$. The primers used for detection of sap9 and sap10 in C. albicans (SAP9F: $5^{\prime}$ ATTTACTCCACAGTTTATATCACTGAAGGT3', SAP9R: 5 CCACCAGAACCACCCTCAGTT 3', SAP10F: 5 CCCGGTATCCAATAGAATCGAA3 and SAP10R: 5`TCAGTGAATGTGACGAATTTGAAGA 3’) were 
purchased from Operon Biotechnologies GmbH Biocompus cologne, Germany ${ }^{23}$.

DNA samples were amplified in $25 \mu \mathrm{L}$ reaction mixture containing $2.5 \mu \mathrm{L}$ DNA, $12.5 \mu \mathrm{L}$ my Taq red mix (Bioline Co., UK), $1 \mu \mathrm{L}$ forward primer $(10 \mu \mathrm{M}), 1 \mu \mathrm{L}$ reverse primer $(10 \mu \mathrm{M})$ and nuclease free water to $25 \mu \mathrm{L}$. the cycling conditions include heating at $94^{\circ} \mathrm{C}$ for $5 \mathrm{~min}$, then 35 cycles of $94^{\circ} \mathrm{C}$ for $10 \mathrm{sec}, 59^{\circ} \mathrm{C}$ for $20 \mathrm{sec}$ and $72^{\circ} \mathrm{C}$ for $30 \mathrm{sec}$ and finally heating at $72^{\circ} \mathrm{C}$ for $3 \mathrm{~min}$. The PCR products as well as GeneRuler 50 bp plus DNA ladder (Thermo scientific, USA) were separated on 1.5\% agarose gel, stained with ethidium bromide, visualized by UV transilluminator and photographed.

\section{Detection of biofilm formation in Candida albicans iso- lates}

The biofilm formation was performed as described previously ${ }^{24}$. Briefly, a colony from each isolate was obtained from the overnight growth on SDA agar plate and inoculated into $5 \mathrm{~mL}$ of Sabouraud broth (SDB). Broths were incubated for $18-20 \mathrm{hr}$ at $37^{\circ} \mathrm{C}$. Yeast cells were twice centrifuged ( $5000 \mathrm{rpm}$ for $5 \mathrm{~min}$ ) and washed with 0.5 $\mathrm{mL}$ phosphate buffer saline (PBS). The cells were re-suspended in $1 \mathrm{~mL} \mathrm{SD}$ broth and adjusted to concentration of $10^{7}$ cells $/ \mathrm{mL}$. Then, $200 \mu \mathrm{L}$ of each isolate suspension was inoculated into individual well of polystyrene 96-well plates, planktonic cells were discarded through three rounds of washing with $200 \mu \mathrm{L}$ sterile PBS buffer, and the plates dried at room temperature for $45 \mathrm{~min}$. For staining, $150 \mu \mathrm{L}$ of $0.4 \%$ Crystal Violet (CV), was added to each well, after $45 \mathrm{~min}$, supernatant was discarded before adding $150 \mu \mathrm{L}$ of $95 \%$ ethanol to dissolve and/or elute CV from the biofilm for $45 \mathrm{~min}$. Finally, $100 \mu \mathrm{L}$ of each well was transferred to a new 96-well microtiter plate and the absorbance at $540 \mathrm{~nm}$ was determined using a microtiter plate reader Synergy HT (BioTek Instruments, Winooski, VT, USA).

For each strain, the mean OD of four wells was calculated (ODt) and also cut-off OD (ODc) was defined as 3 standard deviations above the mean OD of the negative control. The level of biofilm production was determined as follows: non-biofilm producer $(\mathrm{N})$ ODt $\leq$ ODc, weak biofilm producer (W) ODc $<$ ODt $\leq 2 \times$ ODc, moderate biofilm producer (M) $2 \times \mathrm{ODc}<\mathrm{ODt} \leq 4 \times \mathrm{ODc}$ and strong biofilm producer (S) ODt $>4 \times \mathrm{ODc}^{25}$.

\section{Results}

\section{Identification of $C$. albicans isolates}

Fifty three non-duplicate Candida albicans clinical isolates were identified in the present study. The isolates were identified as Candida albicans by PCR. Meanwhile, 51 isolates gave green colonies of Candida albicans on Chromogenic agar and 45 of Candida albicans isolates were germ tube positive. On the other hand, 8 isolates of $C$. albicans were germ tube negative (false negative). Among these isolates 30 were from the respiratory tract, 17 from urinary tract and 6 were from blood samples.

\section{Susceptibility to anti-fungals}

The data presented in table (1), showed the susceptibility of Candida albicans to the different anti-fungal disks. The data revealed that, out of 53 Candida albicans isolates five $(9.4 \%)$ isolates were resistant to three anti-fungal drugs. Approximately, fluconazole and voriconazole show $9.4 \%$, $11.3 \%$ resistance while 5 fluorocytosine show 100\% resistance. On the other hand, both caspofungin and amphotericin B show no resistance.

Table 1

\begin{tabular}{|c|c|c|c|c|c|c|}
\hline \multirow{3}{*}{ Antifungals } & \multicolumn{6}{|c|}{ Number and percentage of $C$. albicans isolates $(n=53)$} \\
\hline & \multicolumn{2}{|c|}{$\mathbf{R}$} & \multicolumn{2}{|c|}{ I } & \multicolumn{2}{|c|}{$\mathbf{S}$} \\
\hline & $\mathbf{N}$ & $\%$ & $\mathbf{N}$ & $\%$ & $\mathbf{N}$ & $\%$ \\
\hline FLU & 5 & 9.4 & 2 & 3.8 & 46 & 86.8 \\
\hline VOR & 6 & 11.3 & 3 & 5.7 & 44 & 83 \\
\hline AMB & 0 & 0 & 2 & 3.8 & 51 & 96.2 \\
\hline 5-FC & 53 & 100 & 0 & 0 & 0 & 0 \\
\hline CASP & 0 & 0 & 1 & 1.9 & 52 & 98.1 \\
\hline
\end{tabular}




\section{Proteolytic and biofilm activity}

The data presented in Fig. (1A) showed that 8 out of 53 isolates of $C$. albicans $(15 \%)$ have strong activity of aspartyl proteinase, 27 isolates have mild activity (51\%), while 18 isolates $(34 \%)$ revealed no aspartyl proteinase activity.
The result of biofilm formation shown in Fig. (1B) revealed that $12(22.6 \%)$ isolates out of 53 were strong biofilm forming. Meanwhile, $1(1.9 \%)$ isolate was moderate and $9(17 \%)$ were weak biofilm producers. In addition, 31 $(58.5 \%)$ isolates were non-biofilm producers.

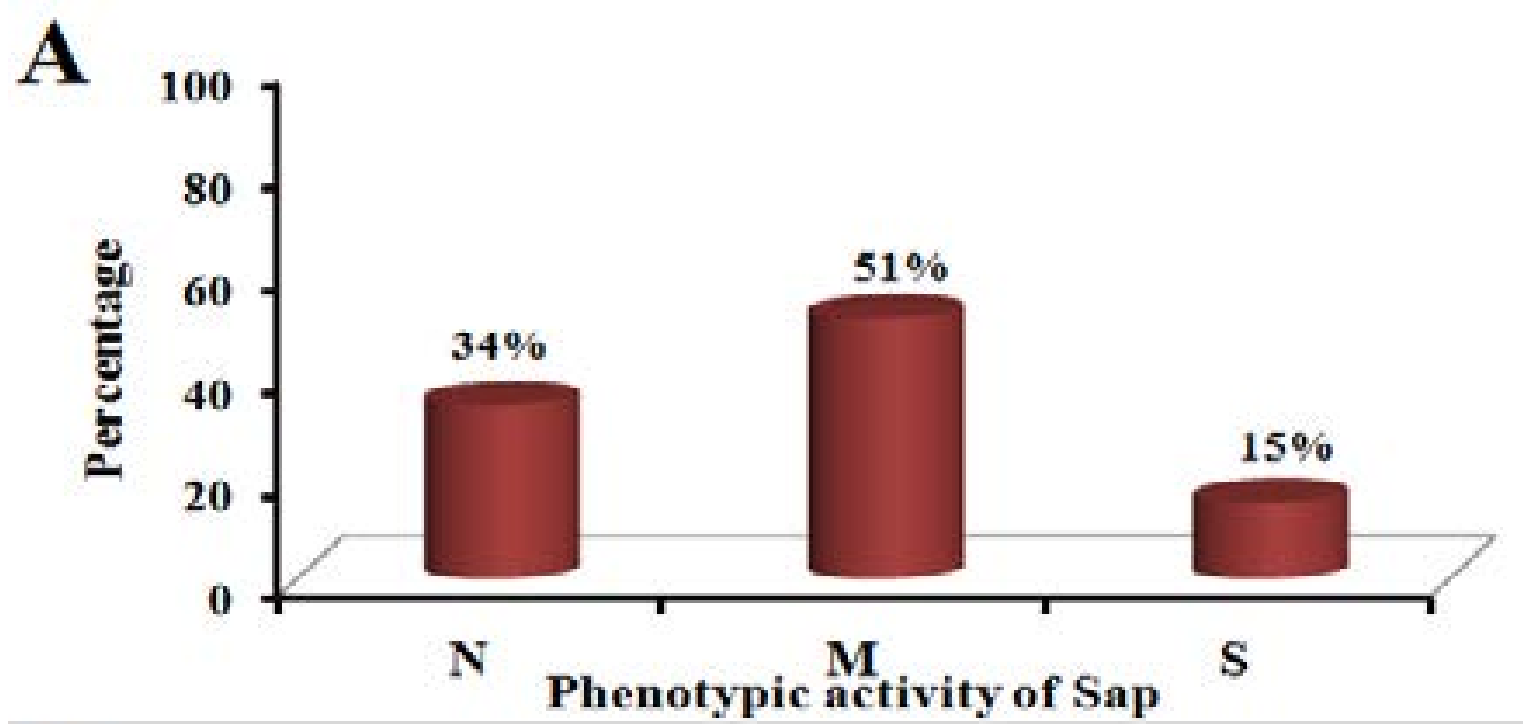

\section{B}

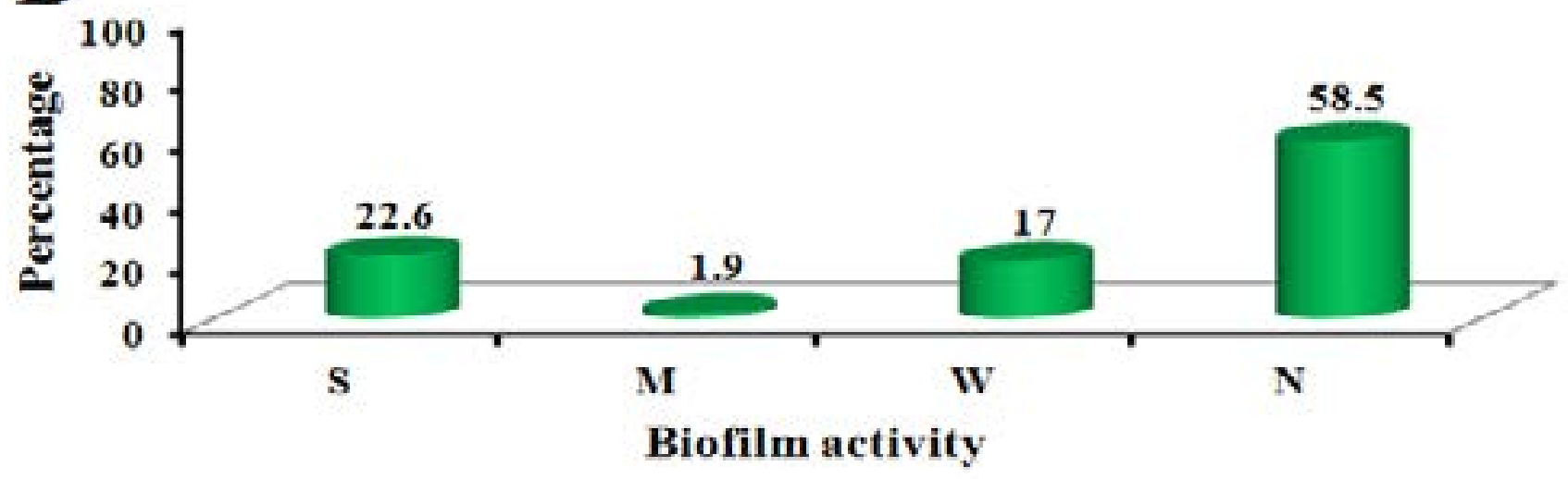

Fig. (1): A: Phenotypic detection of secreted aspartyl protease activity in C. albicans isolates by culturing on bovine serum agar (BSA) agar and incubated at $28^{\circ} \mathrm{C}$ for 7 days and measuring the clearing zone around the growing colony, B: Detection of biofilm activity in C. albicans isolates after biofilm growth on microtiter plate containing Sabouraud broth (SDB) for 48 hours and measure the absorbance at $540 \mathrm{~nm}$ after staining with crystal violet.

Genotypic detection of Sap in C. albicans isolates using PCR

In the present study 53 isolates of C. albicans in addition to standard Candida albicans strain (ATCC10231) were tested for the presence of Sap9 and 10 genes. Sap9 gene was detected in $45(84.9 \%)$ isolates, while Sap10 gene was detected in $42(79.2 \%)$ isolates. Detection of Sap9 and Sap10 genes in the PCR products of Candida albicans isolates on agarose gel at approximately $80 \mathrm{bp}$, as shown in figure (2). 


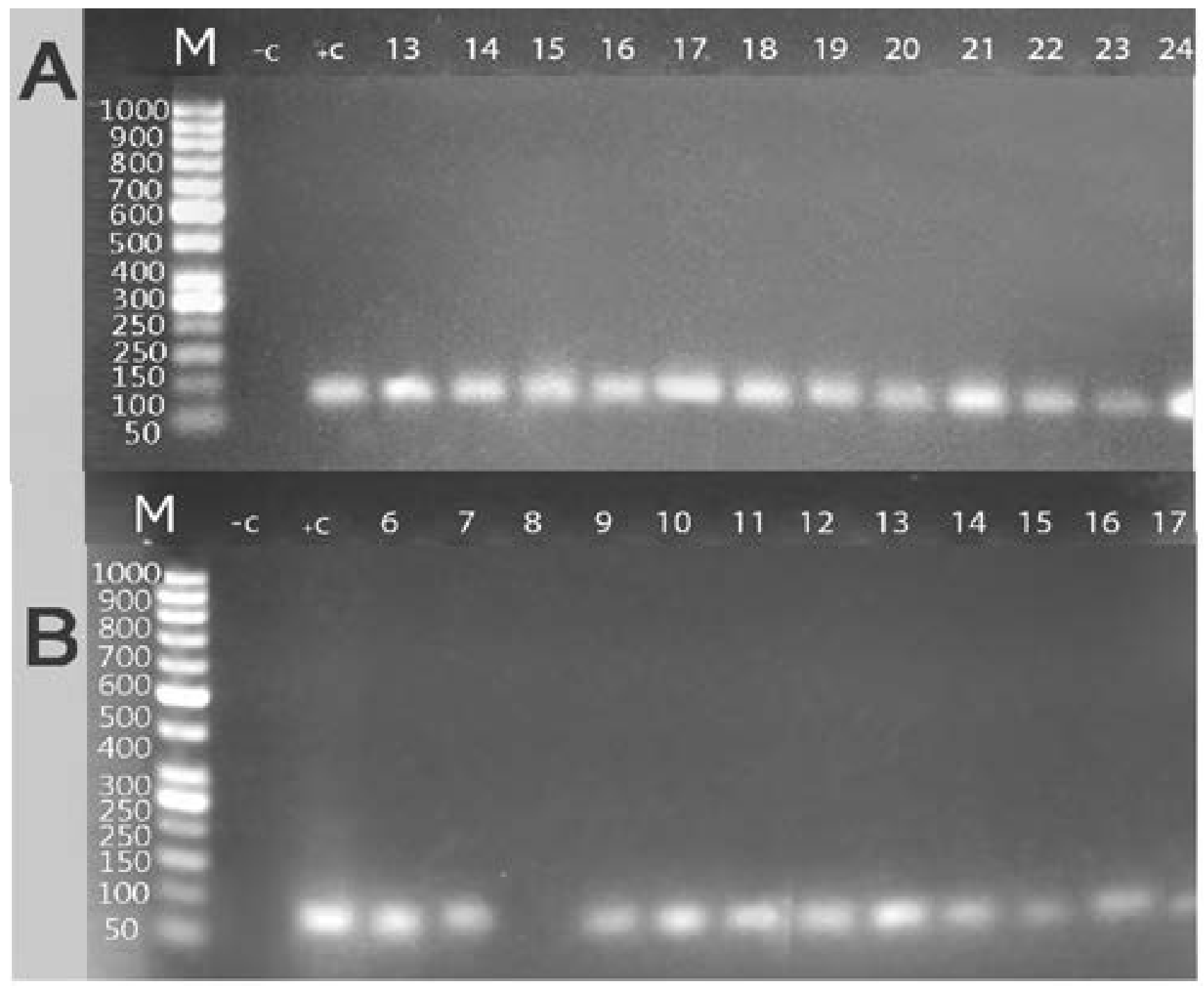

Fig. 2: Electrophoretic graph of conventional PCR products on $1.5 \%$ agarose gel stained with ethidium bromide in some represented $C$. albicans isolates (A: detection of Sap9 gene (80 bp amplicon), B: detection of Sap10 gene (80 bp amplicon). Lane 1 (M): represent 50 bp DNA ladder, Lane 2 (-C): negative control (reagent control mixture without DNA), Lane $3(+C)$ : positive control (reagent control mixture with DNA of standard strain ATCC 10231), Lane 4 to lane 15: clinical C. albicans isolates. DNA was extracted from Clinical $C$. albicans isolated from patients with systemic Candida albicans infections (respiratory tract, urinary tract infections and candidemia).

The data presented in table (2) show that 5 isolates out of 53 isolates were resistant to 3 anti-fungal which have proteolytic activity with prevalence of either Sap9 or Sap10 genes or both; out of these isolates 4 isolates show strong biofilm formation. The rest of isolates (48 isolates) which were resistant to 2 or 1 anti-fungal drugs show strong biofilm formation in only 8 isolates $(16 \%)$, while 30 isolates have proteolytic activity $(65 \%)$. 
Table 2

\begin{tabular}{|c|c|c|c|c|c|c|}
\hline $\begin{array}{c}\text { Isolate } \\
\text { No. }\end{array}$ & Source & $\begin{array}{l}\text { Biofilm } \\
\text { activity }\end{array}$ & $\begin{array}{c}\text { Sap } \\
\text { activity }\end{array}$ & Sap 9 gene & $\begin{array}{l}\text { Sap } 10 \\
\text { gene }\end{array}$ & resistance profile \\
\hline $\mathbf{S T}$ & $\begin{array}{l}\text { ATCC } \\
10231\end{array}$ & $\mathbf{W}$ & + & + & + & $5-\mathrm{FC}$ \\
\hline $\mathbf{1}$ & $\mathbf{R}$ & $\mathbf{N}$ & + & + & + & S-FC \\
\hline 2 & $\mathbf{R}$ & $\mathbf{N}$ & - & + & + & 5-FC \\
\hline 3 & $\mathbf{R}$ & $\mathbf{N}$ & ++ & + & + & $5-\mathbf{F C}$ \\
\hline 4 & $\mathbf{R}$ & $\mathbf{s}$ & ++ & + & + & S-FC, FLU, YOR \\
\hline 5 & $\mathbf{R}$ & $\mathbf{N}$ & + & - & + & $5-F C$ \\
\hline 6 & $\mathbf{R}$ & $\mathbf{N}$ & - & - & + & $5-\mathbf{F C}$ \\
\hline 7 & $\mathbf{R}$ & $\mathbf{N}$ & ++ & + & + & S-FC, FLU, VOR \\
\hline 8 & $\mathbf{R}$ & $\mathbf{N}$ & + & + & - & $5-\mathbf{F C}$ \\
\hline 9 & $\mathbf{R}$ & $\mathbf{N}$ & - & + & + & S-FC, VOR \\
\hline 10 & $\mathbf{R}$ & $\mathbf{N}$ & + & + & + & S-FC \\
\hline 11 & $\mathbf{B}$ & $\mathbf{N}$ & ++ & + & + & S-FC \\
\hline 12 & $\mathbf{R}$ & $\mathbf{N}$ & - & + & + & 5-FC \\
\hline 13 & $\mathbf{R}$ & $\mathbf{N}$ & - & + & + & S-FC \\
\hline 14 & $\mathbf{R}$ & $\mathbf{N}$ & - & + & + & S-FC \\
\hline 15 & $\mathbf{R}$ & $\mathbf{N}$ & + & + & + & S-FC \\
\hline 16 & $\mathbf{R}$ & $\mathbf{w}$ & - & + & + & $5-\mathrm{FC}$ \\
\hline 17 & $\mathbf{R}$ & $\mathbf{N}$ & - & + & + & S-FC \\
\hline 18 & $\mathbf{R}$ & $\mathbf{w}$ & + & + & + & S-FC \\
\hline 19 & $\mathbf{R}$ & $\mathbf{N}$ & + & + & + & S-FC \\
\hline 20 & $\mathbf{R}$ & $\mathbf{w}$ & - & + & + & S-FC \\
\hline 21 & $\mathbf{B}$ & $\mathbf{N}$ & + & + & + & S-FC \\
\hline 22 & $\mathbf{R}$ & $\mathbf{N}$ & - & + & + & S-FC \\
\hline 23 & $\mathbf{R}$ & $\mathbf{N}$ & - & + & + & $5-\mathrm{FC}$ \\
\hline 24 & $\mathbf{B}$ & $\mathbf{N}$ & + & + & + & S-FC \\
\hline 25 & $\mathbf{R}$ & $\mathbf{N}$ & - & + & + & S-FC \\
\hline $\begin{array}{l}26 \\
27\end{array}$ & $\begin{array}{l}\mathbf{R} \\
\mathbf{R}\end{array}$ & $\begin{array}{l}\mathbf{W} \\
\mathbf{N}\end{array}$ & $\begin{array}{l}+ \\
+\end{array}$ & $\begin{array}{l}+ \\
+\end{array}$ & $\begin{array}{l}+ \\
+\end{array}$ & $\begin{array}{l}\text { S-FC } \\
5-F C\end{array}$ \\
\hline 28 & $\mathbf{R}$ & $s$ & ++ & + & - & S-FC, FLU, YOR \\
\hline 29 & $\mathbf{R}$ & $\mathbf{w}$ & - & + & - & $5-F C$ \\
\hline 30 & $\mathbf{B}$ & $\mathbf{N}$ & + & + & - & $5-\mathrm{FC}$ \\
\hline 31 & $\mathbf{R}$ & $\mathbf{N}$ & + & + & - & $5-\mathrm{FC}$ \\
\hline 32 & $\mathbf{R}$ & $\mathbf{N}$ & - & + & - & $5-\mathrm{FC}$ \\
\hline 33 & $\mathbf{R}$ & $\mathbf{N}$ & + & + & + & 5-FC \\
\hline 34 & $\mathbf{R}$ & $\mathbf{N}$ & - & - & + & $5-\mathbf{F C}$ \\
\hline 35 & $\mathbf{B}$ & $\mathbf{N}$ & - & + & + & $5-\mathrm{FC}$ \\
\hline 36 & $\mathbf{B}$ & $\mathbf{s}$ & + & + & + & S-FC \\
\hline 37 & $\mathbf{U}$ & $\mathbf{w}$ & + & + & + & $5-\mathbf{F C}$ \\
\hline 38 & $\mathbf{U}$ & $\mathbf{s}$ & + & + & - & S-FC, FLU, YOR \\
\hline 39 & u & $\mathbf{s}$ & + & + & + & $5-F C$ \\
\hline 40 & U & M & + & + & + & S-FC \\
\hline 41 & $\mathbf{U}$ & $\mathbf{s}$ & + & + & + & $5-\mathrm{FC}$ \\
\hline 42 & U & $\mathbf{s}$ & + & + & + & S-FC \\
\hline 43 & U & $\mathbf{w}$ & - & - & - & S-FC \\
\hline 44 & U & $s$ & + & - & - & $5-\mathrm{FC}$ \\
\hline 45 & $\mathbf{U}$ & $s$ & + & - & + & $5-\mathrm{FC}$ \\
\hline 46 & $\mathbf{U}$ & $s$ & ++ & + & + & 5-FC \\
\hline 47 & U & $\mathbf{N}$ & ++ & + & + & S-FC \\
\hline 48 & U & $\mathbf{N}$ & + & + & + & $5-\mathrm{FC}$ \\
\hline 49 & U & $\mathbf{w}$ & + & - & + & S-FC \\
\hline 50 & U & $\mathbf{N}$ & - & + & - & S-FC \\
\hline 51 & U & $\mathbf{w}$ & + & - & - & S-FC \\
\hline 52 & $\mathbf{U}$ & $\mathbf{s}$ & ++ & + & + & $5-F C$ \\
\hline 53 & U & $\mathbf{s}$ & + & + & + & S-FC, FLU, YOR \\
\hline
\end{tabular}




\section{Discussion}

The aim of this work was to determine the relationship between the anti-fungal susceptibility in one side, and the biofilm formation as well as the secretion of aspartic proteinases on the other side which represent major determinants associated with the pathogenicity of Candida species.

The available therapies against fungal diseases are limited and classified into five classes that have different targets in the fungal cells; polyenes, azoles and allylamines target cell membrane, while pyrimidine analogs target the fungal DNA and RNA. In contrast the new class echinocandins target the fungal cell wall ${ }^{26}$.

Prolonged usage of azole anti-fungals in treating infections caused by $C$. albicans has led to the emergence of resistance. The acquisition of azole resistance in clinical isolates of C. albicans generally results in Multi-Drug (MDR) Resistance ${ }^{27,28}$.

The presence of MDR in fungal pathogens is a serious complication during treatment of opportunistic fungal infections and poses a vital threat to the present therapeutic regimes by limiting the number of clinically useful anti-fungal drugs ${ }^{29}$.

Biofilm formation in C. albicans has a major rule in pathogenesis which allows Candida to adhere to mucosal cells and polymeric surfaces of medical devices leading to spread of nosocomial infections. Biofilm forming cells are characterized by a three-dimensional structure that can survive the immune system of the host and associated with increasing the resistance to anti-fungal drugs ${ }^{30}$. The mechanism of biofilm resistance to anti-microbial agents is not fully understood. One hypothesis supposed that the formation of polysaccharide matrix has negative effect on the drugs penetration to fungal cells by formation of strong barrier ${ }^{31}$, and only the outer layers are in contact with lethal doses of anti-fungals ${ }^{5}$.

Interestingly, a correlation between anti-fungal susceptibility and biofilm formation was observed in four out of the five resistant clinical isolates in this work. These isolates were strong biofilm producers and revealed resistant to 3 anti-fungal drugs which in agreement with that reported by Bitar et al. ${ }^{32}$, and Nobile and Mitchell ${ }^{33}$. They confirmed that the high resistance to fluconazole was usually associated with biofilm formation in C. albicans isolates. This correlation could be explained based on many mechanisms including active extrusion by efflux pumps $^{34}$.

Severe candidiasis is correlated to the production of extracellular hydrolytic enzymes which have a vital role in the pathogenesis of the yeasts ${ }^{35,36}$.

Aspartyl proteases are one of the major virulence factors in C. albicans that reported to have a role in tissue invasion, hyphal formation, adherence, and phenotypic switching ${ }^{10}$. Many evidences prove the role of Sap enzymes in pathogenicity which include; the infected patients with C. albicans have higher proteolytic activity than asymptomatic carriers, in the other hand, the HIV infected patients with C. albicans have high proteolytic activity ${ }^{10}$. Severe candidiasis is correlated to the production of extracellular hydrolytic enzymes which have a vital role in the pathogenesis of the yeasts ${ }^{35,36}$.

Furthermore a correlation between reduced susceptibility to anti-fungal agents and aspartyl proteinase production was confirmed in this study where all resistant isolates to the anti-fungals under investigations were aspartyl proteinase producers. In addition $80 \%$ of these isolates were biofilm producers.

The current study revealed other correlation between prevalence of Sap9 and Sap10 genes and the strong biofilm producers by C. albicans isolates, as $66.7 \%$ of these isolates have both Sap9 and Sap10, while 25\% have either Sap9 or Sap10. One isolate $(8.3 \%)$ has neither Sap9 nor Sap10. Previous result was consistent with that reported by Chaffin ${ }^{37}$ and Schild et al. ${ }^{17}$, in which the Sap9 and Sap10 mediate biofilm formation. Silva et al. ${ }^{38}$, proved that pathogenicity is related to biofilm formation which is a likely indicator of growth, production of hydrolytic enzymes as well as resistance to anti-microbial activity. Furthermore, Rajendran et al. $^{39}$ found a correlation between higher SAP productions and increase the adhesion to buccal cells as well as resistance to fluconazole of $C$. albicans isolates.

Another study made a correlation between the extracellular proteolytic activity in vitro and the virulence of Candida species and prove that only the most virulent species such as C. albicans, C. tropicalis and C. parapsilosis produce more proteinases in vitro than do less virulent species ${ }^{40}$.

African Health Sciences Vol 18 Issue 4, December, 2018 


\section{Conclusion}

Our study represents an advance in biomedical and health science by observing a link between the reduction in susceptibility to anti-fungal drugs and the virulence indicated by pathogenic $C$. albicans isolates mainly including the biofilm formation and Sap production.

\section{Disclosure statement}

No potential conflict of interest is reported by the authors.

\section{References}

1. Bassetti M, Righi E, Montravers P, Cornely O. What has changed in the treatment of invasive candidiasis? A look at the past 10 years and ahead. Journal of Antimicrobial Chemotherapy. 2018; 73(1): i14-i25.

2. Lai CC, Wang CY, Liu WL, Huang WL, Hsueh PR. Time to positivity of blood cultures of different Candida species causing fungaemia. Journal of medical microbiology. 2012; 61: 701-704.

3. Pfaller MA, Diekema DJ. Epidemiology of invasive candidiasis: a persistent public health problem. Clinical Microbiology Reviews. 2007; 20(1): 133-163.

4. Odds FC, Gow NAR, Brown AJP. Toward a molecular understanding of Candida albicans virulence. In: Heitman J, Filler SG, Edwards JE Jr, Mitchell AP (eds) Molecular principles of fungal pathogenesis. Washington, DC, ASM Press; 2006;. 305-319.

5. Sardi JC, Scorzoni L, Bernardi T, Fusco-Almeida AM, Giannini MJS. Candida species: current epidemiology, pathogenicity, biofilm formation, natural antifungal products and new therapeutic options. Journal of medical Microbiology. 2013; 62:10-24.

6. White TC, Agabian N. Candida albicans secreted aspartyl proteinases: isoenzyme pattern is determined by cell type, and levels are determined by environmental factors. Journal of Bacteriology. 1995; 177:5215-5221.

7. Calderone RA, Gow NAR. Host recognition by Candida species. In: Calderone R.A. (ed) Candida and candidiasis. Washington: ASM Press; 2002.; 67-86. PubMed.

8. Calderoni RA, Fonzi WA. Virulence factors of Candida albicans. Trends in Microbiology. 2001; 9: 327-335.

9. Schaller M, Schackert C, Korting HC, Januschke E, Hube, B. Invasion of Candida albicans correlates with expression of secreted aspartic proteinases during experimental infection of human epidermis. Journal of Investigative Dermatology. 2000; 114:712-717.

10. Naglik JR, Challacombe SJ, Hube B. Candida albi- cans secreted aspartyl proteinases in virulence and pathogenesis. Microbiology and Molecular Biology Reviews. 2003 ; 67:400 - 428.

11. Ray TL, Payne CD. Comparative production and rapid purification of Candida acid proteinase from protein-supplemented cultures. Infection and Immunity. 1990; 58: 508-514.

12. Parra-Ortega B, Cruz-Torres H, Villa-Tanaca L, Hernández-Rodríguez C. Phylogeny and evolution of the aspartyl protease family from clinically relevant Candida species. Memórias do Instituto Oswaldo Cruq. 2009; 104: 505-512.

13. Sacristan B, Blanco MT, Galan-Ladero MA, Blanco J, Perez-Giraldo C, Gomez-Garcia AC. Aspartyl proteinase, phospholipase, hemolytic activities and biofilm production of Candida albicans isolated from bronchial aspirates of ICU patients. Medical Mycology. 2011; 49(1): 94-97.

14. Naglik JR, Moyes D, Markwana J, Kanzaria P, Tsichlaki E, Weindl G, et al. Quantitative expression of the Candida albicans secreted aspartyl proteinase gene family in human oral and vaginal candidiasis. Microbiology. 2008; 154: 3266-3280.

15. Nailis H, Kucharikova S, Ricicova M, Van Dijck P, Deforce D, Nelis H, et al. Real-time PCR expression profiling of genes encoding potential virulence factors in Candida albicans biofilms: identification of model dependent and independent gene expression. BMC Microbiology. 2010; 10: 114 .

16. Mathe L, Van Dijck P. Recent insights into Candida albicans biofilm resistance mechanisms. Current Genetics. 2013; 59:251-264.

17. Schild L, Heyken A, de Groot PW, Hiller E, Mock M, de Koster C, et al. Proteolytic cleavage of covalently linked cell wall proteins by Candida albicans Sap9 and Sap10. Eukaryotic Cell. 2011; 10: 98-109.

18. Cheesbrough M. Microbiological Tests. In: Cheesbrough, M., Ed., District Laboratory Practice in Tropical Countries, Part II, Low Priced Edition, Cambridge, Cambridge University Press; 2000; 105-130.

19. Kadry A, El-Ganiny A, El-Baz A. Comparison of methods used in identification of Candida albicans. Research Journal of Pharmacy and Technology. (In press).

20. Clinical and Laboratory Standards Institute (CLSI). Method for anti-fungal disk diffusion susceptibility testing of yeasts: approved guideline, $2^{\text {nd }}$ edition, Clinical and Laboratory Standards Instituite, Wayne, Pa 2009; M44-A2.

21. Al-Hedaithy SS. Spectrum and proteinase production 
of yeast causing vaginitis in Saudi Arabian woman. Medical Science Monitor. 2002; 8: 498-501.

22. Marinho SA, Teixeira AB, Santos OS, Cazanova RF, Ferreira CAS, Cherubini K, et al. Identification of candida spp. by phenotypic tests and PCR. Brazilian Journal of $M i$ crobiology. 2010; 41: 286-294.

23. Monroy-Pérez E, Paniagua-Contreras G, Vaca-Paniagua F, Negrete-Abascal E, Vaca S. SAP Expression in Candida albicans Strains Isolated from Mexican Patients with Vaginal Candidosis. International Journal of Medical Medicine. 2013; 4: 25-31.

24. Younes S, Bahnan W, Dimassi HI, Khalaf RA. The Candida albicans Hwp2 is necessary for proper adhesion, biofilm formation and oxidative stress tolerance. Microbiological Research. 2011; 166(5):430-436.

25. Stepanovic' S, Vukovic' D, Hola V, Di Bonaventura G, Djukic S, Cirkovic I, et al. Quantification of biofilm in microtiter plates: overview of testing conditions and practical recommendations for assessment of biofilm production by Staphylococci. Journal of Pathology, Microbiology and Immunology. 2007; 115: 891-899.

26. Denning DW, Hope WW. Therapy for fungal diseases: opportunities and priorities. Trends in Microbiology. 2010; 18:195-204.

27. White TC, Marr KA, Bowden RA. Clinical, cellular, and molecular factors that contribute to antifungal drug resistance. Clinical Microbiology Reviews. 1998; 11: 382-402.

28. Franz R, Ruhnke M, Morschhauser J. Molecular aspects of fluconazole resistance development in Candida albicans. Mycoses. 1999; 42: 453-458.

29. Cowen LE. The evolution of fungal drug resistance: modulating the trajectory from genotype to phenotype. Nature Reviews Microbiology. 2008; 6: 187-198.

30. Ingles DO, Skvzypek MS, Arnaudetal MB. Improved gene ontology annotation for biofilm form, filamentous growth, and phenotypic switching in Candida albicans. Eukaryotic Cell. 2013; 12(1):101-108.
31. Kojic EM, Darouiche RO. Candida infections of medical devices. Clinical Microbiology Reviews. 2004; 17 : 255-267.

32. Bitar I, Khalaf RA, Harastani H, Tokajian S. Identification, typing, antifungal resistance profile, and biofilm formation of Candida albicans isolates from Lebanese hospital patients. BioMed Research International.2014; 2014: 931372, 10 pages.

33. Nobile CJ, Mitchell AP. Genetics and genomics of Candida albicans biofilm formation. Cellular Nicrobiology. 2006; 8: 1382-1391.

34. Ramage G, Rajendran R, Sherry L, Williams C. Fungal biofilm resistance. International Journal of Medical Microbiology. 2012; 2012: 528521, 14 pages.

35. Bramono K, Yamazaki M, Tsuboi R, Ogawa H. Comparison of proteinase, lipase and alpha-glucosidase activities from the clinical isolates of Candida species. Japanese Journal of Infectious Disease. 2006; 59:73-76.

36. Ingham CJ, Boonstra S, Levels S, de Lange M, Meis JF, Schneeberger PM. Rapid susceptibility testing and microcolony analysis of Candida spp. cultured and imaged on porous aluminum oxide. PLOS ONE. 2012; 7(3): e33818. 37. Chaffin WL. Candida albicans cell wall proteins. Microbiology and Molecular Biology Reviews 2008; 72:495 -544 .

38. Silva S, Henriques M, Oliveira R, Williams D, Azeredo J. In Vitro Biofilm Activity of Non-Candida albicans Candida Species. Current Microbiology. 2010; 61:534-540.

39. Rajendran R, Robertson DP, Hodge PJ, Lappin DF, Ramage G. Hydrolytic enzyme production is associated with Candida albicans biofilm formation from patients with type I diabetes. Mycopathologia. 2010; 70: 229-235.

40. Ruchel R. Proteinase. In J. E. Bennett, R. J. Hay, and P. K. Peterson (ed.), New strategies in fungal disease. Churchill Livingstone, Edinburgh, United Kingdom; 1992; 17-31. 